\title{
Your role in early diagnosis \& Tx of metastatic bone disease
}

\section{This approach to the work-up and diagnosis will help you to ensure prompt treatment while maximizing your patient's quality of life.}

\section{PRACTICE RECOMMENDATIONS \\ $>$ Initiate appropriate lab and imaging work-ups for any patient without known malignancy who has a suspicious bone lesion. (c) \\ > Prescribe protected weight- bearing for the patient who has a painful bone lesion, and refer promptly to an orthopedic surgeon to prevent pathologic fracture. (C) \\ Strength of recommendation (SOR) \\ (A) Good-quality patient-oriented evidence \\ B Inconsistent or limited-quality patient-oriented evidence \\ C Consensus, usual practice opinion, disease-oriented evidence, case series}

$\mathrm{S}$ ince the early 1990s, modern treatments have steadily reduced overall cancer mortality from primary tumors. ${ }^{1}$ Consequently, more people are at risk of metastatic bone disease, with subsequent pain and pathologic fractures $^{1,2}$ and death from metastasis. ${ }^{3}$ Patients who have bone metastases present with a variety of signs and symptoms including pain, fractures, and metabolic derangements. The primary care approach to work-up and diagnosis described in this article enables prompt treatment, either surgical or nonsurgical, to maintain a high quality of life for patients.

\section{Primary tumors determine}

\section{types of metastases and prognosis}

Metastasis, a complex pathologic process in which cancerous cells migrate to distant organs, implant, and grow, ${ }^{3}$ is a poor prognostic indicator in cancer patients. Bone is the third most common site of metastasis, behind the liver and lungs. ${ }^{4}$ While the true prevalence of metastatic bone cancer is unknown, studies have estimated it to be $>280,000$ cases in the United States. ${ }^{5}$

Bone metastases interfere with normal bone metabolism and turnover in several different characteristic patterns. These changes-radiographically defined as osteoblastic, osteolytic, or mixed lesions-are determined by the primary tumor type.

- Osteoblastic lesions, comprised of new, disorganized bone formation, often occur secondary to prostate cancer, small cell lung cancer, and carcinoid malignancies, among others.

- Osteolytic lesions, in which bone is destroyed, are more common with breast cancer, renal cell carcinoma, melanoma, and multiple myeloma.

- Mixed lesions, in which areas of bone destruction and
Daniel Reinhardt, MD; Brant Ansley, MSPAS; Humza Mian, BA; Jacob Brubacher, MD; Kyle Sweeney, MD Department of Orthopedic Surgery, University of Kansas Medical Center, Kansas City

\section{\#ksweeney2@kumc.edu}

The authors reported no potential conflict of interest relevant to this article. 


\section{$>$}

When a patient presents with signs and symptoms suggestive of metastatic bone disease, inquire about a history of cancer-even if such a history is remote. It's important. growth are simultaneously found, occur with some GI cancers and a few breast cancers. ${ }^{6,7}$

I Most bone metastases result from carcinomas, of which up to $50 \%$ eventually spread to bone, although this process can take 10 to 15 years. ${ }^{8,9}$ The likelihood of bone metastasis depends on the primary tumor and its stage. Breast and prostate cancer account for most skeletal metastases, although these lesions are often asymptomatic. ${ }^{6,9}$ Other malignancies, such as ovarian and gastrointestinal, metastasize to bone much less frequently. ${ }^{7,10}$ Virtually any cancer at an advanced stage can spread to bone. These metastases are usually multifocal and incurable, with the patient's prognosis varying from a few months to years. ${ }^{6,11,12}$

I Factors that influence prognosis. Metastatic bone disease arising from melanoma and lung cancers has the shortest life expectancy of roughly 6 months from initial diagnosis; metastasis following prostate, breast, and thyroid cancers has the longest, usually 2 to 4 years. ${ }^{11}$ TABLE $1^{13}$ shows survival estimates from a large Danish population at various time points following bone metastasis diagnosis for several primary cancer types.

When surgical intervention for bony metastasis is required, prognosis is generally poorer, likely due to more advanced disease. The overall 1-year survival following surgery varies, but several large studies have found a rate of around $40 \%$ when considering all primary tumors. ${ }^{14,15}$ The most common metastases, from breast and prostate cancers, have 1 -year survivals of around $50 \%$ and $30 \%$, respectively, following surgical intervention. ${ }^{16-18}$

\section{What you're likely to see on presentation}

Bone metastases are one of the leading causes of morbidity in cancer patients from resultant pain, pathologic fractures, metabolic derangements, and reduced activities of daily living. ${ }^{8,19}$ The most common cause of cancer pain is bone involvement. ${ }^{6}$ Patients report pain that is usually worse at night, poorly localized, and not alleviated with rest. They often mistakenly relate the pain to an injury..$^{20}$ The pathophysiology of bone pain is not completely understood but is likely multifactorial and includes inflammatory and mechanical processes. ${ }^{7,21}$ Spine involvement can lead to stenosis or nerve root compression, with symptoms dependent on level and severity of nerve or cord compromise..$^{20}$ Overall, the most common site of bone metastasis is the thoracic spine, followed by the ribs, pelvis, and proximal long bones. ${ }^{20}$

I Pathologic fractures occur frequently in cancer patients. Bone destruction leads to a loss of mechanical support which, in turn, causes microfractures and pain. These microfractures can proliferate and coalesce, causing a pathologic fracture, often in weight-bearing bones. ${ }^{6}$ Breast cancer with lytic lesions is the single leading cause of all pathologic fractures. ${ }^{22}$ Lung cancer with its short survival time and prostate cancer with blastic lesions are less common causes. ${ }^{23}$ In the appendicular skeleton, the vast majority of these fractures occur in the femur and humerus. ${ }^{11}$

I Symptomatic metabolic derangements. The most common metabolic disorder is hypercalcemia, found predominantly in patients with hematologic malignancies, squamous cell lung cancer, renal cell cancer, and breast cancer. ${ }^{6,7,12,24}$ The clinical presentation is nonspecific and can include polyuria, polydipsia, fatigue, constipation, and confusion. The prevalence is estimated to be $13 \%$ in breast cancer, $4 \%$ in lung cancers, and $1 \%$ in prostate cancer, although results in individual studies vary. ${ }^{12}$ The pathophysiology is multifactorial and often includes osteolytic lesions and an increased circulating level of parathyroid hormone-related peptide, although other mechanisms contribute. ${ }^{25,26}$ Ultimately, severe hypercalcemia may be fatal secondary to renal failure and cardiac arrhythmias. ${ }^{6,7,12}$ Paraneoplastic hypercalcemia independently decreases survival; 1 study found the median survival to be 10 to 12 weeks. ${ }^{11}$

\section{Primary care work-up and diagnosis}

When a patient presents with signs and symptoms suggestive of metastatic bone disease, inquire about a history of cancer. Even if such a history is remote, it is important- 
TABLE 1

One-year, 3-year, and 5-year survival estimates after bone metastasis diagnosis (all) by primary cancer type $\mathrm{e}^{13}$

\begin{tabular}{l|l|l|l}
\hline & 1 -year survival \% $(95 \% \mathrm{Cl})$ & 3 -year survival $\%(95 \% \mathrm{Cl})$ & 5 -year survival \% $(95 \% \mathrm{Cl})$ \\
\hline $\begin{array}{l}\text { Digestive organs } \\
\text { Colon }\end{array}$ & $21(18-25)$ & $7(5-10)$ & $3(2-5)$ \\
Rectum & $22(18-26)$ & $3(2-5)$ & $2(1-3)$ \\
\hline Lung & $10(9-11)$ & $2(1-2)$ & $1(0.5-1)$ \\
\hline Malignant melanoma & $17(12-22)$ & $6(4-10)$ & $5(3-8)$ \\
\hline Breast & $51(50-53)$ & $25(23-26)$ & $13(11-14)$ \\
\hline Female genital organs & $18(11-28)$ & $6(2-14)$ & $2(0-7)$ \\
Cervix & $33(21-44)$ & $15(7-25)$ & $8(3-18)$ \\
Ovary & $35(34-37)$ & $12(11-13)$ & $6(5-7)$ \\
\hline Prostate & & $10(8-12)$ & $5(4-7)$ \\
\hline Urinary organs & $29(26-33)$ & $5(3-7)$ & $3(1-5)$ \\
\hline Kidney & $13(11-17)$ & & 5 \\
Bladder & & & \\
\hline
\end{tabular}

$\mathrm{Cl}$, confidence interval

${ }^{a}$ Including the rectosigmoid colon.

Adapted with permission from: Svensson et al. BMJ Open. 2017. ${ }^{13}$

particularly so if the patient received chemotherapy or radiation, which can lead to secondary cancers such as leukemia or sarcoma. ${ }^{20}$ If a primary site of malignancy is unknown, pursue a general review of systems. Clues to the primary site of disease could be a history of chest pain, shortness of breath, hemoptysis, heat/cold intolerance, or changes in bowel/bladder habits. Also ask about risk factors such as smoking, chemical exposure, and sun exposure.

I Pointers on radiographic imaging. If you suspect a destructive bone lesion, order appropriate radiographic imaging. Arrange for plain radiographs with at least 2 views of the specific area of interest that include the entire bone along with the joints above and below. Importantly, the entire bone must be imaged before any surgical procedure to avoid periprosthetic fractures from undetected bone metastases around hardware. ${ }^{20}$ Keep in mind that plain films can miss early lesions, and computed tomography (CT) or magnetic resonance imaging (MRI) may be needed if suspicion of a pathologic process is still strong and especially if a primary malignancy is known. ${ }^{27}$

\section{Working back to a primary diagnosis}

If imaging confirms a suspicious lesion and the patient has no known primary tumor, order labs, a CT scan with contrast of the chest, abdomen, and pelvis, and a bone scan, and refer the patient to an oncologist. If the bone lesion is painful, initiate protected weightbearing and additionally refer the patient to an orthopedic surgeon.

I Appropriate laboratory evaluation entails a complete blood count; metabolic panel that includes serum calcium and phosphorus, vitamin $\mathrm{D}$, alkaline phosphatase, thyroid-stimulating hormone, and parathyroid hormone; and serum protein electrophoresis to rule out multiple myeloma. ${ }^{7,11}$ Tumor markers are useful to monitor a patient's response to cancer treatment or to determine recurrence, but they play only a limited role in the initial work-up of an unknown bone tumor. ${ }^{28}$

I Further imaging. A CT scan with intravenous contrast of the chest, abdomen, and pelvis is done to screen for visceral malignancy; however, $15 \%$ of bone lesions in patients with an unknown primary lesion never have a source identified.$^{29}$ Bone scans can be useful 


\section{$>$}

Order plain radiographs if you suspect a bone lesion. Request at least 2 views of the area that include the entire bone with the joints above and below. in identifying the extent of a single lesion seen on plain films and to assess for additional asymptomatic lesions. Additional imaging-eg, CT or MRI of the lesion, or positron emission tomography (PET) - can be left to the discretion of the oncologist or surgeon.

CT scans have significantly higher sensitivity than radiographs and offer better visualization of bone quality, bone destruction, and soft-tissue extension. ${ }^{30}$ MRI can be used to assess changes in bone marrow and softtissue involvement. PET scans, which detect tumors by quantifying metabolic activity, remain controversial. PET is superior to bone scans in detecting bone metastases from lung and breast cancers, but worse in renal and prostate cancers due to slow growth of metastases. ${ }^{31-33}$

Caveat. Do not assume that a bone lesion is metastatic. Delayed diagnosis of a primary bone tumor can lead to significant changes in clinical course and patient outcome. ${ }^{34}$ If any doubt exists as to the type of lesion, arrange for a biopsy using proper technique and delay bone fixation until a histologic diagnosis is complete. ${ }^{35}$ Biopsy may be performed via image-guided fine-needle aspiration, core biopsy, or open incisional biopsy.

\section{Treatment options}

Metastatic bone disease is typically managed nonsurgically with radiation, chemo- or immunotherapies, hormone suppression, bone-modifying agents, or ablation. ${ }^{36}$ An overview of the cancer treatment guidelines for bone metastasis from the 2017 National Comprehensive Cancer Network is shown in TABLE 2 . $^{36}$

Radiotherapy can take the form of external-beam or radioisotope radiation. With localized irradiation, most patients who have painful lesions experience at least partial relief, often within a few weeks. ${ }^{12,37}$ It may be used postoperatively, as well, to decrease the chances of disease progession. ${ }^{20}$

Systemic therapies include chemoand hormone therapies. Chemotherapy effectiveness is highly dependent on the primary tumor type. For example, renal cell carcinoma and melanoma are often resistant, while lymphoma and germ-cell tumors may be eliminated and sometimes even cured. ${ }^{7}$ Hormone therapy can be highly effective in selective cancers, primarily breast and prostate cancers. Immunotherapy options may also be used to specifically target bone metastasis sites.

Bone-modifying agents include bisphosphonates and denosumab (Prolia, Xgeva). These are generally initiated at the discretion of the oncologist, but primary care physicians should be familiar with their use. Bisphosphonates, which includes zoledronic acid, pamidronate, and other agents, are analogues of pyrophosphate that inhibit bone demineralization. ${ }^{38}$ These agents target bone resorption through incorporation into osteoclasts and have been effective in the treatment of hypercalcemia and bone lesions. ${ }^{6,12,39}$ Not only do they reduce the incidence of all skeleton-related events, including pathologic fractures and pain, they also appear to have antitumor activity with prolonged survival in certain cancers. ${ }^{7,12}$

Denosumab, which has a much shorter half-life than bisphosphonates, is a monoclonal antibody that targets the gene RANKL, a key activator of osteoclasts, and thereby prevents the development of osteoclasts and related bone resorption. ${ }^{40}$

r Radiofrequency ablation or cryoablation, using image-guided needle placement, specifically targets individual bone lesions, destroying tumor cells with extreme heat or cold, respectively. This has been shown to reduce pain and opioid consumption. ${ }^{41}$

\section{Managing pain}

Pain management can be difficult, especially as patients live longer and undergo additional treatments such as surgery, radiation, and chemotherapy, each with the potential to produce chronic pain. ${ }^{42} \mathrm{~A}$ multidisciplinary team with a stepwise and multimodal approach can improve the patient's function and comfort while decreasing drug adverse effects. $^{43}$

For mild-to-moderate pain, nonsteroidal anti-inflammatory drugs, acetaminophen, and tramadol may provide effective relief. For more severe pain, narcotics are often required on a fixed-dose schedule along with 
TABLE 2

\section{Treatment options for various types of bone metastatic cancers ${ }^{36}$}

\begin{tabular}{|c|c|c|c|c|c|c|}
\hline & Prostate & Breast & Renal & Lung & Thyroid & Multiple myeloma \\
\hline $\begin{array}{l}\text { Systemic } \\
\text { therapy }\end{array}$ & Yes & Yes & Yes & Yes & Yes & Yes \\
\hline $\begin{array}{l}\text { Bone } \\
\text { targeted }\end{array}$ & $\begin{array}{l}\text { Denosumab } \\
\text { Zoledronic acid } \\
\text { Radium-223 }\end{array}$ & $\begin{array}{l}\text { Denosumab } \\
\text { Zoledronic acid } \\
\text { Pamidronate }\end{array}$ & $\begin{array}{l}\text { Denosumab } \\
\text { Zoledronic acid }\end{array}$ & $\begin{array}{l}\text { Consider: } \\
\text { Denosumab } \\
\text { Zoledronic acid }\end{array}$ & $\begin{array}{l}\text { Denosumab } \\
\text { Pamidronate } \\
\text { Zoledronic acid }\end{array}$ & $\begin{array}{l}\text { Pamidronate } \\
\text { Zoledronic acid }\end{array}$ \\
\hline Radiation & Yes & Yes & Yes & Yes & Yes & Yes \\
\hline Vitamins & $\begin{array}{l}\text { Calcium, } \\
\text { vitamin D }\end{array}$ & $\begin{array}{l}\text { Calcium, } \\
\text { vitamin D }\end{array}$ & $\begin{array}{l}\text { Calcium, } \\
\text { vitamin D }\end{array}$ & $\mathrm{N} / \mathrm{A}$ & $\mathrm{N} / \mathrm{A}$ & N/A \\
\hline Notes & $\begin{array}{l}\text { Possible use of } \\
\text { Sr-89 or Sm-153 }\end{array}$ & & & & $\begin{array}{l}\text { Consider } \\
\text { embolization } \\
\text { before surgical } \\
\text { resection to reduce } \\
\text { hemorrhage }\end{array}$ & \\
\hline
\end{tabular}

N/A, not available; Sm-153, samarium-153; Sr-89, strontium-89.

Adapted with permission from: Gdowski et al. J Exp Clin Cancer Res. 2017.36

breakthrough options such as short-acting hydromorphone, oxycodone, or transmucosal fentanyl. ${ }^{42-44}$ Opioid adverse effects such as constipation and nausea/vomiting must be managed with laxatives and metoclopramide/antidopaminergics, respectively.

Other important non-narcotic therapies are corticosteroids, tricyclic antidepressants, gabapentin, neuroleptics, and nerve blocks. ${ }^{45}$ Physical therapy and acupuncture may also be useful, depending on the patient's needs and desires. Despite the wide range of options, most patients continue to have a significant amount of pain that can impact daily activities and even cause them to feel that their quality of life was not an important factor in physician decision making. ${ }^{46}$

\section{Surgery options}

Surgical intervention for metastatic bone disease differs from its use in primary bone tumors in that clinical indications are not clearly defined. In general, surgery for metastatic disease is used in patients who have pathologic fractures, a risk of pathologic fracture, or uncontrolled cancer-induced bone pain. Keep in mind that the overarching goal of surgery is to reduce morbidity, not mortality, although exceptions exist. Metastatic renal cell carcinoma is one such exception: improved survival may be achieved via ag- gressive surgical resection for solitary or oligometastatic lesions. ${ }^{47}$

I Before deciding on surgery, engage the patient in goals-of-care discussions and take into account factors specific to the individual, as operative complications can be devasting. Risk of postoperative infection is high, given that these patients are often immunocompromised and that irradiated tissue is prone to wound healing issues. ${ }^{8}$ Complications may require a pause in chemotherapy and a subsequent decrease in life expectancy.

Another factor in surgical decision making is that newer systemic therapies are leading to longer survival for those with various types of metastatic cancer. ${ }^{48}$ Older methods of fixation designed to last a few years may now fail during the patient's prolonged lifespan. As novel therapies continue to improve survival and complicate surgical indications, it may be prudent for the surgical management of metastatic bone disease to be handled by fellowship-trained orthopedic oncologists.

I Factors that affect timing. Surgical intervention ideally occurs before the development of a pathologic fracture. Outcomes research has shown that intervention before fracture leads to reduced blood loss and length of hospital stay with improved functional recovery and survival. ${ }^{12,49}$ Despite 


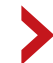

\section{If a patient with no known primary tumor has a confirmed bone lesion, order labs, a CT scan with contrast of the chest, abdomen, and pelvis, and a bone scan.}

these improved outcomes, an adequate scoring system to guide surgical intervention has yet to be developed. Mirels' criteria are cited most often, yet this scoring system fails to account for many important considerations such as primary tumor type, life expectancy, and other factors. ${ }^{50,51}$

Given the deleterious effects of fractures in cancer patients and the inadequacy of closed reduction and immobilization, surgical intervention is often warranted..$^{52}$ Surgical technology has continued to progress; however, intramedullary nailing, plating, and endoprostheses are still the most commonly used methods. ${ }^{53}$

Intramedullary nailing is commonly used in the prophylactic treatment of pathologic lesions and fractures of long bones in patients whose expected survival is as little as 6 to 12 weeks. ${ }^{54}$ Plate and screw fixation is a viable alternative to intramedullary nailing when tumor resection is desired. Endoprostheses replacement is used when a tumor involves joint surfaces or if biological reconstruction cannot be achieved by nailing or plating.

\section{Explicit communication \\ with patients is critical}

Of vital importance is your participation with patients and families in shared decision making throughout the diagnostic and treatment process, ensuring clear communication. Misunderstandings about cancer stages and prognoses are not uncommon and are sometimes due to insufficient explanation. ${ }^{55,56}$ Additionally, expectations of survival and adverse effects of treatment often differ greatly between physicians and patients, which can lead to patient dissatisfaction. ${ }^{57}$

Finally, the long-term care of patients with metastatic cancers necessarily involves multidisciplinary teams, which further complicates communication. To ensure that patients are receiving an appropriate course of treatment, evaluate their health literacy, confirm their understanding of the disease, and acknowledge their desires.

JFP

\section{CORRESPONDENCE}

Kyle Sweeney, MD, University of Kansas Medical Center,

Department of Orthopedic Surgery, 3901 Rainbow Boulevard, MS 3017, Kansas City, KS 66160; ksweeney2@kumc.edu.

\section{References}

1. Siegel RL, Miller KD, Jemal A. Cancer statistics, 2017. CA Cancer JClin. 2017;67:7-30.

2. Miller KD, Siegel RL, Lin CC, et al. Cancer treatment and survivorship statistics, 2016. CA Cancer J Clin. 2016;66:271-289.

3. Chambers AF, Naumov GN, Varghese HJ, et al. Critical steps in hematogenous metastasis: an overview. Surg Oncol Clin N Am. 2001;10:243-255.

4. Coleman RE. Metastatic bone disease: clinical features, pathophysiology and treatment strategies. Cancer Treat Rev. 2001;27:165-176

5. Li S, Peng Y, Weinhandl ED, et al. Estimated number of prevalent cases of metastatic bone disease in the US adult population. Clin Epidemiol. 2012;4:87-93.

6. Coleman RE. Clinical features of metastatic bone disease and risk of skeletal morbidity. Clin Cancer Res. 2006;12:6243s-6249s.

7. Macedo F, Ladeira K, Pinho F, et al. Bone metastases: an overview. Oncol Rev. 2017;11:321.

8. Wood TJ, Racano A, Yeung H, et al. Surgical management of bone metastases: quality of evidence and systematic review. Ann Surg Oncol. 2014;21:4081-4089.

9. Virk MS, Lieberman JR. Tumor metastasis to bone. Arthritis Res Ther. 2007;9(suppl 1):S5.

10. Suva LJ, Washam C, Nicholas RW, et al. Bone metastasis: mechanisms and therapeutic opportunities. Nat Rev Endocrinol. 2011;7:208-218.

11. Selvaggi G, Scagliotti GV. Management of bone metastases in cancer: a review. Crit Rev Oncol Hematol. 2005;56:365-378.

12. Shibata H, Kato S, Sekine I, et al. Diagnosis and treatment of bone metastasis: comprehensive guideline of the Japanese Society of Medical Oncology, Japanese Orthopedic Association, Japanese Urological Association, and Japanese Society for Radiation Oncology. ESMO Open. 2016;1:e000037.

13. Svensson E, Christiansen CF, Ulrichsen SP, et al. Survival after bone metastasis by primary cancer type: a Danish populationbased cohort study. BMJ Open. 2017;7 e016022.

14. Ratasvuori M, Wedin R, Keller J, et al. Insight opinion to surgically treated metastatic bone disease: Scandinavian Sarcoma Group Skeletal Metastasis Registry report of 1195 operated skeletal metastasis. Surg Oncol. 2013;22:132-138.

15. Hansen BH, Keller J, Laitinen M, et al. The Scandinavian Sarcoma Group Skeletal Metastasis Register. Survival after surgery for bone metastases in the pelvis and extremities. Acta Orthop Scand Suppl. 2004;75:11-15.

16. Dürr HR, Müller PE, Lenz T, et al. Surgical treatment of bone metastases in patients with breast cancer. Clin Orthop Relat Res. 2002:191-196.

17. Weiss RJ, Tullberg E, Forsberg JA, et al. Skeletal metastases in 301 breast cancer patients: patient survival and complications after surgery. Breast. 2014;23:286-290.

18. Weiss RJ, Forsberg JA, Wedin R. Surgery of skeletal metastases in 306 patients with prostate cancer. Acta Orthop. 2012;83:74-79.

19. Nathan SS, Chan L, Tan WL, et al. The need for a system of prognostication in skeletal metastasis to decide best end-of-life care - a call to arms. Ann Acad Med Singapore. 2010;39:476-481.

20. Weber KL. Evaluation of the adult patient (aged $>40$ years) with a destructive bone lesion. J Am Acad Orthop Surg. 2010;18:169-179.

21. Clohisy DR, Mantyh PW. Bone cancer pain. Cancer. 2003;97 (3 suppl):866-873.

22. McDuffee LA, Colterjohn N, Singh G. Bone metastasis and pathological fractures. In: Singh G, Rabbani SA, eds. Bone Metastasis. Experimental and Clinical Therapeutics. Totowa, NJ: Humana Press; 2005:229-241.

23. Nielsen OS, Munro AJ, Tannock IF. Bone metastases: pathophysiology and management policy. J Clin Oncol. 1991;9:509-524.

24. Maisano R, Pergolizzi S, Cascinu S. Novel therapeutic approaches to cancer patients with bone metastasis. Crit Rev Oncol Hematol. 2001;40:239-250.

25. Marino MT, Asp AA, Budayer AA, et al. Hypercalcaemia and elevated levels of parathyroid hormone-related protein in cutaneous squamous/basal cell carcinoma. J Intern Med. 1993;233:205-207.

26. Grill V, Ho P, Body JJ, et al. Parathyroid hormone-related protein: elevated levels in both humoral hypercalcemia of malignancy and hypercalcemia complicating metastatic breast cancer. J Clin Endocrinol Metab. 1991;73:1309-1315.

27. Jehn CF, Diel IJ, Overkamp F, et al. Management of metastatic 
bone disease algorithms for diagnostics and treatment. Anticancer Res. 2016;36:2631-2637.

28. Molina R, Bosch X, Auge JM, et al. Utility of serum tumor markers as an aid in the differential diagnosis of patients with clinical suspicion of cancer and in patients with cancer of unknown primary site. Tumour Biol. 2012;33:463-474.

29. Rougraff BT, Kneisl JS, Simon MA. Skeletal metastases of unknown origin. a prospective study of a diagnostic strategy. J Bone Joint Surg Am. 1993;75:1276-1281.

30. Rybak LD, Rosenthal DI. Radiological imaging for the diagnosis of bone metastases. Q J Nucl Med. 2001;45:53-64.

31. Marom EM, McAdams HP, Erasmus JJ, et al. Staging non-small cell lung cancer with whole-body PET. Radiology. 1999;212: 803-809.

32. Yang SN, Liang JA, Lin FJ, et al. Comparing whole body (18)F2-deoxyglucose positron emission tomography and technetium$99 \mathrm{~m}$ methylene diphosphonate bone scan to detect bone metastases in patients with breast cancer. J Cancer Res Clin Oncol. 2002;128:325-328.

33. Schirrmeister $\mathrm{H}$, Guhlmann A, Elsner $\mathrm{K}$, et al. Sensitivity in detecting osseous lesions depends on anatomic localization: planar bone scintigraphy versus 18F PET. J Nucl Med. 1999;40: 1623-1629.

34. Adams SC, Potter BK, Mahmood Z, et al. Consequences and prevention of inadvertent internal fixation of primary osseous sarcomas. Clin Orthop Relat Res. 2009;467:519-525.

35. Scolaro JA, Lackman RD. Surgical management of metastatic long bone fractures: principles and techniques. J Am Acad Orthop Surg. 2014;22:90-100.

36. Gdowski AS, Ranjan A, Vishwanatha JK. Current concepts in bone metastasis, contemporary therapeutic strategies and ongoing clinical trials. J Exp Clin Cancer Res. 2017;36:108.

37. Yoon F, Morton GC. Single fraction radiotherapy versus multiple fraction radiotherapy for bone metastases in prostate cance patients: comparative effectiveness. Cancer Manag Res. 2014;6: $451-457$.

38. Coleman RE, Smith P, Rubens RD. Clinical course and prognostic factors following bone recurrence from breast cancer. BrJCancer. 1998;77:336-340.

39. Van Acker HH, Anguille S, Willemen Y, et al. Bisphosphonates for cancer treatment: mechanisms of action and lessons from clinical trials. Pharmacol Ther. 2016;158:24-40.

40. Castellano D, Sepulveda JM, Garcia-Escobar I, et al. The role of RANK-ligand inhibition in cancer: the story of denosumab. On cologist. 2011;16:136-145.

41. Guenette JP, Lopez MJ, Kim E, et al. Solitary painful osseous metastases: correlation of imaging features with pain palliation afte radiofrequency ablation-a multicenter American College of Radiology imaging network study. Radiology. 2013;268:907-915.
42. Glare PA, Davies PS, Finlay E, et al. Pain in cancer survivors. J Clin Oncol. 2014;32:1739-1747.

43. ASATFCPM, ASRAPM. Practice guidelines for chronic pain management: an updated report by the American Society of Anesthesiologists Task Force on Chronic Pain Management and the American Society of Regional Anesthesia and Pain Medicine. Anesthesiology. 2010;112:810-833.

44. Fallon M, Giusti R, Aielli F, et al. Management of cancer pain in adult patients: ESMO clinical practice guidelines. Ann Oncol. 2018;29(suppl 4):ivl66-iv191.

45. Kvale PA, Simoff M, Prakash UBS, ACCP. Lung cancer. Palliative care. Chest. 2003;123(1 suppl):284S-311S

46. Breivik H, Cherny N, Collett B, et al. Cancer-related pain: a panEuropean survey of prevalence, treatment, and patient attitudes. Ann Oncol. 2009;20:1420-1433.

47. Kato S, Murakami H, Takeuchi A, et al. Fifteen-year survivor of renal cell carcinoma after metastasectomies for multiple bone metastases. Orthopedics. 2013;36:e1454-e1457.

48. Harrington KD. Orthopedic surgical management of skeletal complications of malignancy. Cancer. 1997;80 (8 suppl):1614-1627.

49. Ristevski B, Jenkinson RJ, Stephen DJG, et al. Mortality and complications following stabilization of femoral metastatic lesions: a population-based study of regional variation and outcome. Can J Surg. 2009;52:302-308.

50. Mirels H. Metastatic disease in long bones: a proposed scoring system for diagnosing impending pathologic fractures. 1989. Clin Orthop Relat Res. 2003(415 suppl):S4-S13.

51. Jawad MU, Scully SP. In brief: classifications in brief: Mirels classification: metastatic disease in long bones and impending pathologic fracture. Clin Orthop Relat Res. 2010;468:2825-2827.

52. Gainor BJ, Buchert P. Fracture healing in metastatic bone disease Clin Orthop Relat Res. 1983:297-302.

53. Bird JE. "Advances in the surgical management of bone tumors." Curr Oncol Rep. 2014;16:392.

54. Bickels J, Dadia S, Lidar Z. Surgical management of metastatic bone disease. J Bone Joint Surg Am. 2009;91:1503-1516.

55. Kim SH, Shin DW, Kim SY, et al. Terminal versus advanced cancer: do the general population and health care professionals share a common language? Cancer Res Treat. 2016;48 759-767.

56. Lee JK, Yun YH, An AR, et al. The understanding of terminal cancer and its relationship with attitudes toward end-of-life care issues. Med Decis Making. 2014;34:720-730.

57. Lux MP, Bayer CM, Loehberg CR, et al. Shared decision-makin in metastatic breast cancer: discrepancy between the expected prolongation of life and treatment efficacy between patients and physicians, and influencing factors. Breast Cancer Res Treat. 2013;139:429-440. 